\title{
An automated microinfiltrometer to measure small-scale soil water infiltration properties
}

\author{
Dennis C. Gordon ${ }^{1}$, Paul D. Hallett ${ }^{1,2^{*}}$ \\ ${ }^{1}$ The James Hutton Institute, Invergowrie, Dundee, DD2 5DA, United Kingdom. \\ ${ }^{2}$ Present address: Institute of Biological and Environmental Sciences, University of Aberdeen, Cruickshank Building, St Machar Drive, \\ Aberdeen, AB24 3UU, United Kingdom. \\ * Corresponding author. Tel.: +44 (0)1224 272264. Fax: +44 (0)1224 272703. E-mail: paul.hallett@abdn.ac.uk
}

\begin{abstract}
We developed an automated miniature constant-head tension infiltrometer that measures very small infiltration rates at millimetre resolution with minimal demands on the operator. The infiltrometer is made of $2.9 \mathrm{~mm}$ internal radius glass tube, with an integrated bubbling tower to maintain constant negative head and a porous mesh tip to avoid air-entry. In the bubbling tower, bubble formation and release changes the electrical resistance between two electrodes at the air-inlet. Tests were conducted on repacked sieved sands, sandy loam soil and clay loam soil, packed to a soil bulk density $\rho_{\mathrm{d}}$ of $1200 \mathrm{~kg} \mathrm{~m}^{-3}$ or $1400 \mathrm{~kg} \mathrm{~m}^{-3}$ and tested either air-dried or at a water potential $\psi$ of $-50 \mathrm{kPa}$. The change in water volume in the infiltrometer had a linear relationship with the number of bubbles, allowing bubble rate to be converted to infiltration rate. Sorptivity measured with the infiltrometer was similar between replicates and showed expected differences from soil texture and $\rho_{\mathrm{d}}$, varying from $0.15 \pm 0.01$ (s.e.) $\mathrm{mm} \mathrm{s}^{-1 / 2}$ for $1400 \mathrm{~kg} \mathrm{~m}^{-3}$ clay loam at $\psi=-50 \mathrm{kPa}$ to $0.65 \pm 0.06 \mathrm{~mm} \mathrm{~s}^{-1 / 2}$ for $1200 \mathrm{~kg} \mathrm{~m}^{-3}$ air dry sandy loam soil. An array of infiltrometers is currently being developed so many measurements can be taken simultaneously.
\end{abstract}

Keywords: Tension infiltrometer; Water sorptivity; Automated measurements; Small-scale infiltration measurements.

\section{INTRODUCTION}

The temporal and spatial variability of soil water infiltration complicates measurements and predictions of hydrological processes (Bowker et al., 2013; Logsdon and Jaynes, 1996). At catchment scale, differences in parent material and soil properties within a slope drive spatial variability (Doerr et al., 2002; Thompson et al., 1998). Biological processes, such as soil fauna and root channels, can also have a large impact on the spatial variability of water infiltration (Bowker et al., 2013). Over time, soil water infiltration changes due to the pore structure dynamics driven by cycles of wetting and drying, farming or other land management practices and biological processes (Hallett et al., 2013). Conventional water infiltration measurements, with standard infiltrometers, can quantify spatial variability at metre resolution and its temporal dynamics (Zhao et al., 2011). Much smaller scale variability in water infiltration at millimetre resolution has also been observed, which has been attributed to pore structure heterogeneity (Or and Tuller, 1999). The coating of pore surfaces with organic coatings that cause hydrophobicity has also been demonstrated to affect the spatial heterogeneity of early time water infiltration (Hallett et al., 2004) and soil-water contact angles (Bachmann et al., 2013) at millimetre resolution. These measurements rely on specialised approaches using either a miniature infiltrometer or direct measurements of water droplet shape on a soil surface, respectively.

A challenge with measuring the spatial variability of water infiltration at any scale is the number of measurements required. This is exacerbated if temporal variability is also to be measured, resulting in a time-consuming and tedious task. Automated infiltrometers, first developed decades ago (Pittman and Kohnke, 1942), allow for multiple measurements to be conducted by one operator or for measurements on soils where water infiltration is very slow (Johnson et al., 2005). Various designs of automated infiltrometers have been developed, with the sim- plest using a pressure transducer to measure the rate of water loss from an infiltrating falling head (Arriaga et al., 2010). Steady-state tension infiltrometers have also been developed that measure water infiltration directly with microflowmeters (Moret-Fernandez et al., 2012), indirectly from pressure transducers located in the air and water of a Mariotte bottle (Casey and Derby, 2002; Madsen and Chandler, 2007; Prieksat et al., 1992), or from the height of the water column in the infiltrometer measured using TDR (Moret et al., 2004) or infrared sensors (Milla and Kish, 2006). Very sophisticated infiltrometers that change hydraulic head (Moret-Fernandez et al., 2012) and refill automatically (Castiglione et al., 2005) have also been developed.

The technologies used in automated infiltrometers to date, however, may not be appropriate for microinfiltrometers designed for small-scale spatial measurements. In much larger infiltrometers, Spongrova et al. (2009) observed that a largerdiameter reservoir greatly reduced noise when infiltration was assessed with pressure transducers. Due to the very small water volumes that infiltrate from a microinfiltrometer, the reservoir diameter needs to be small. This also precludes the use of TDR because of boundary effects from a small diameter reservoir and of microflowmeters because of low flow rates. In this paper we report a very simple and inexpensive design of a constant head microinfiltrometer that can be constructed easily and recorded with a conventional data-logger. The system measures the rate of bubbling from the air-entry tube in the Mariotte bottle. From electrical resistivity measurements, the growth and release of each bubble can be detected.

\section{MATERIALS AND METHODS}

A diagram and photograph of the microinfiltrometer is illustrated in Figure 1. It consists of a sealed bubble chamber connected by a Mariotte tube to the infiltrating water reservoir. A $5 \mathrm{ml}$ Burette with $0.05 \mathrm{ml}$ gradients was used for the water 


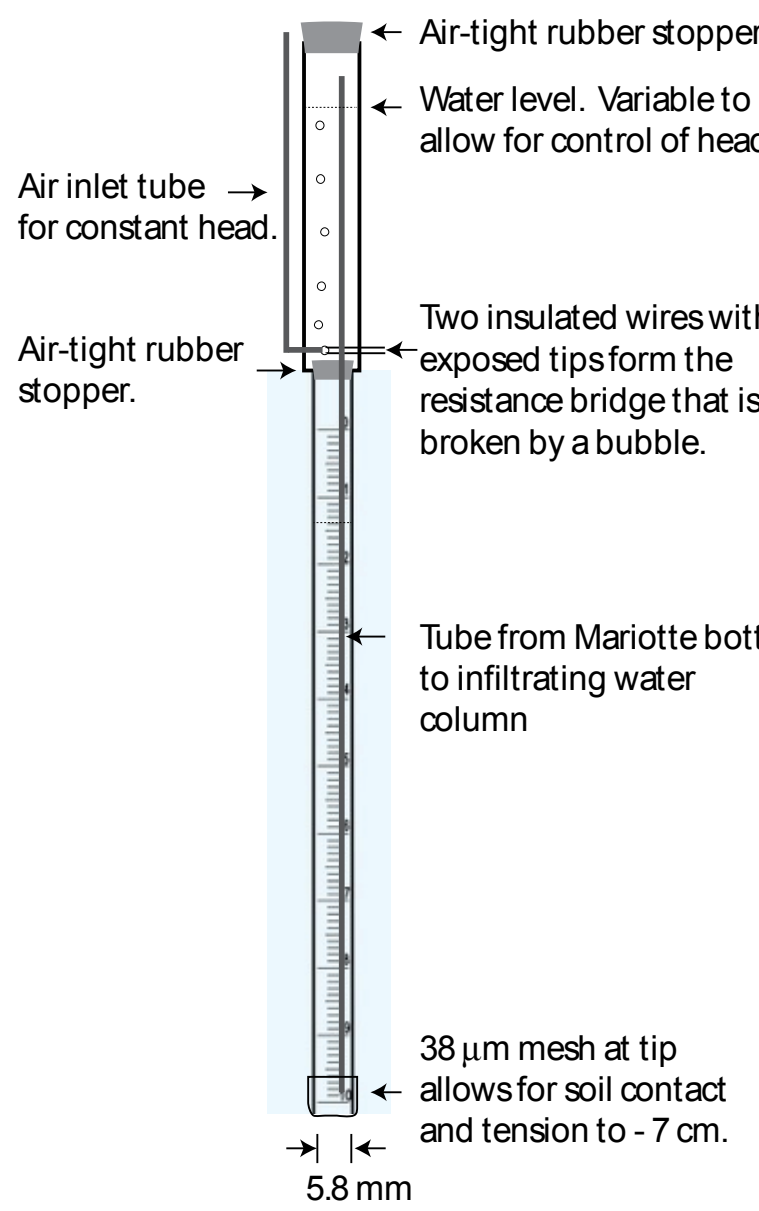

(a)

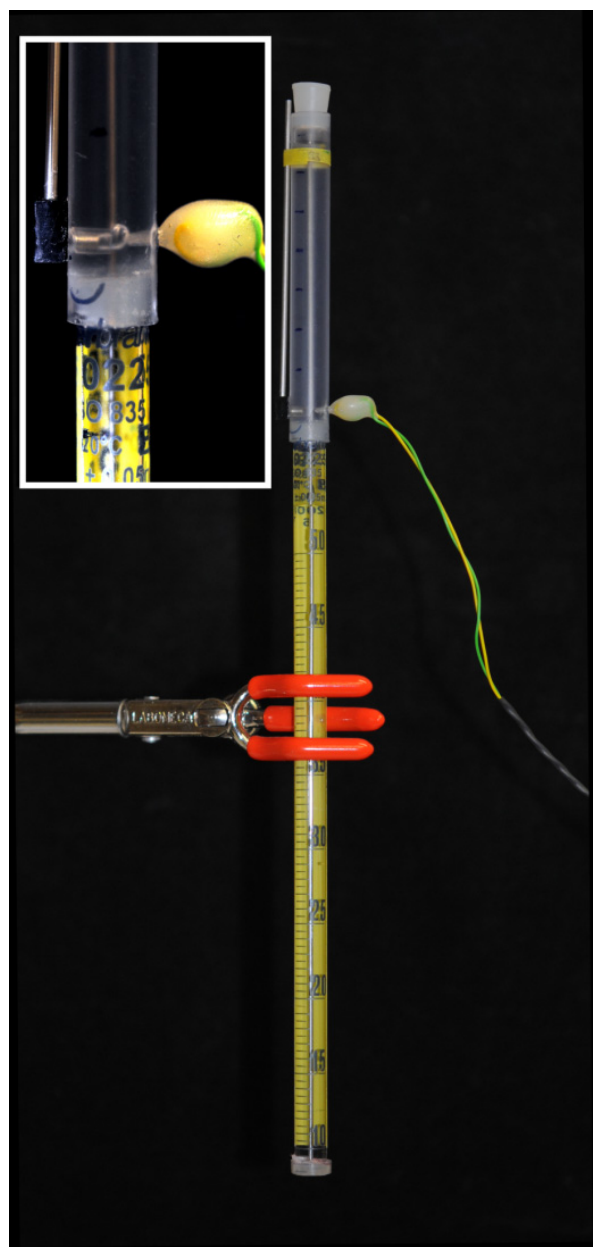

(b)

Fig. 1. The design of the microinfiltrometer shown as a line drawing (a) and photograph (b). The inset in (b) shows a growing bubble in contact with the insulated wires used to measure resistance.

reservoir. The air tubes are constructed from stainless steel tubing used for hypodermic needles (Needle Gauge 20, 0.90 $\mathrm{mm}$ outer diameter and $0.64 \mathrm{~mm}$ inner diameter). The tip of the infiltrometer has a radius $r$ of $2.9 \mathrm{~mm}$ and is covered with $38 \mu \mathrm{m}$ nylon mesh to allow for the rapid flow of water and the establishment of a tension head down to $-7 \mathrm{~cm}$.

As water infiltrates into the soil from the infiltrometer, air bubbles are drawn from the atmosphere to the bubble chamber to balance air pressure. A plastic tube with an inner diameter of $0.90 \mathrm{~mm}$ was placed over the outlet of the air-entry tube to increase bubble size. When a bubble grows at the outlet it eventually breaks the electrical contact between two wires. Each wire is connected to a negative or positive terminal of a $12 \mathrm{~V}$ DC power source, with the negative wire connected to a data acquisition system. A Labview program detects each major drop in electrical resistance and records the corresponding time. Each resistance drop indicates the growth of a new bubble.

The microinfiltrometer was tested using commercial sands and repacked soils that were initially air-dried and passed through a $2 \mathrm{~mm}$ sieve. A sandy loam soil (Dystric-Fluvic Cambisol) and clay loam soil (Gleyic Cambisol) sampled from fields under arable production were used. The sandy loam soil was packed using a compression platen into a $40 \mathrm{~mm}$ diameter by

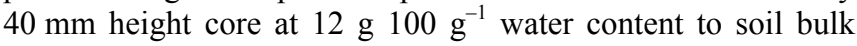

densities $\rho_{\mathrm{d}}$ of $1200 \mathrm{~kg} \mathrm{~m}^{-3}$ and $1400 \mathrm{~kg} \mathrm{~m}^{-3}$. The clay loam soil

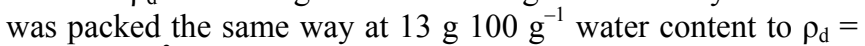
$1400 \mathrm{~kg} \mathrm{~m}^{-3}$. The packed soil specimens were then either dried at $40^{\circ} \mathrm{C}$ until water loss ceased or equilibrated on a sand table to a water potential $\psi$ of $-50 \mathrm{kPa}$.

Infiltration measurements with the microinfiltrometer were conducted with water at tension heads of $-2 \mathrm{~cm}$ or $-7 \mathrm{~cm}$. Measurements lasted from 300 seconds to 900 seconds, depending on the rate of water infiltration. The water volume in the infiltrometer reservoir was recorded manually at least 5 times during the infiltration measurement to allow for calibration between the bubbling rate and water infiltration. However, the aim in practice was to limit measurements so that water volumes would only need to be checked periodically, and not for each measurement. The bubbling rate versus time was recorded and then transformed into water volumes by comparing to the manual readings of water infiltration. On some specimens we recorded very frequent water volume changes, which were used to investigate the linearity of bubbling rate to water volume, which tested whether bubble volume was homogeneous during testing. The infiltrometer was clamped to a retort stand for laboratory tests to ensure it was vertical and to minimise movement. 
Table 1. Properties of the repacked and sieved soils used to test the infiltrometer, including sorptivity calculated using Eq. (1).

\begin{tabular}{|c|c|c|c|c|c|c|c|c|c|c|c|}
\hline \multirow[t]{2}{*}{ Soil } & \multirow{2}{*}{$\begin{array}{c}\text { Bulk } \\
\text { density, } \\
\rho_{\mathrm{d}} \\
\left(\mathrm{kg} \mathrm{m}^{-3}\right)\end{array}$} & \multicolumn{2}{|c|}{$\begin{array}{l}\text { Water content } \\
\qquad\left(\mathrm{g} \mathrm{g}^{-1}\right)\end{array}$} & \multicolumn{2}{|c|}{$\begin{array}{l}\text { Air-filled } \\
\text { porosity, } f \\
\left(\mathrm{~m}^{3} \mathrm{~m}^{-3}\right)\end{array}$} & \multicolumn{2}{|c|}{$\begin{array}{l}\text { Infiltration rate, } Q \\
\qquad\left(\mu l \mathrm{~s}^{-1}\right)\end{array}$} & \multicolumn{2}{|c|}{$\begin{array}{c}\text { Sorptivity, } \\
S \\
\left(\mathrm{~mm} \mathrm{~s}^{-1 / 2}\right)\end{array}$} & \multirow[t]{2}{*}{$\begin{array}{l}\text { Infiltrometer } \\
\text { head } \\
(\mathrm{cm})\end{array}$} & \multirow[t]{2}{*}{$\begin{array}{c}\text { Water } \\
\text { potential, } \\
\psi\end{array}$} \\
\hline & & Mean & $\begin{array}{c}\text { Standard } \\
\text { Error }\end{array}$ & Mean & $\begin{array}{l}\text { Standard } \\
\text { Error }\end{array}$ & Mean & $\begin{array}{l}\text { Standard } \\
\text { Error }\end{array}$ & Mean & $\begin{array}{c}\text { Standard } \\
\text { Error }\end{array}$ & & \\
\hline Sandy & 1200 & 0.010 & 0.001 & 0.535 & 0.001 & 5.21 & 1.02 & 0.65 & 0.06 & -7 & Dry \\
\hline loam & 1200 & 0.135 & 0.003 & 0.386 & 0.004 & 1.56 & 0.18 & 0.30 & 0.02 & -7 & $-50 \mathrm{kPa}$ \\
\hline & 1400 & 0.021 & 0.002 & 0.443 & 0.002 & 6.32 & 0.95 & 0.64 & 0.05 & -7 & Dry \\
\hline & 1400 & 0.154 & 0.007 & 0.255 & 0.010 & 1.22 & 0.14 & 0.22 & 0.01 & -7 & $-50 \mathrm{kPa}$ \\
\hline Clay & 1400 & 0.016 & 0.005 & 0.450 & 0.006 & 1.33 & 0.15 & 0.30 & 0.02 & -2 & Dry \\
\hline loam & 1400 & 0.150 & 0.006 & 0.367 & 0.007 & 0.41 & 0.06 & 0.15 & 0.01 & -7 & $-50 \mathrm{kPa}$ \\
\hline & 1400 & 0.000 & 0.000 & 0.547 & 0.000 & 0.24 & 0.06 & 0.13 & 0.02 & -7 & Dry \\
\hline
\end{tabular}

From bubbling data we evaluated the infiltration rate $Q\left(\mu \mathrm{ls}^{-1}\right)$. This was used to calculate water sorptivity $S\left(\mathrm{~mm} \mathrm{~s}^{-1}\right)$, using the equation from (Leeds-Harrison et al., 1994):

$S=\sqrt{\frac{Q f}{4 b r}}$

where $f$ is the air-filled porosity $\left(\mathrm{m}^{3} \mathrm{~m}^{-3}\right)$, and $b$ accounts for the shape of the wetting front, which was taken as 0.55 as suggested as an average value by Wooding (1968).

\section{RESULTS AND DISCUSSION}

The bubbling rate varied between the different soil treatments examined, suggesting greater infiltration to dry and less dense soils $(P<0.001$; Figure 2$)$. Over the time range that measurements were taken, the bubbling rate was highly linear, with $R^{2}$ consistently $>0.98$ for all soil treatments and infiltrometer tensions. A comparison between the cumulative number of bubbles and frequent manual measurements of liquid volume change in the infiltrometer shows a highly linear trend, from which the bubble volume can be calculated (Figure 3). The bubble volume was affected by soil type and soil water status $(P<0.001)$, but not the bulk density or hydraulic head of the infiltrometer.

Table 1 summarises the bubbling and water infiltration results for the different soil treatments that were measured with the microinfiltrometer. $Q$ was calculated from the bubbling rate and bubble volume, which was then transformed into $S$ using Eq. 1. For an individual soil treatment the standard error of $S$ was small, indicating good repeatability between measurements.

Measuring liquid volume changes in the infiltrometer at the start and end of an individual test is feasible, but it does present an extra task for the operator. A comparison between bubbling rate and $S$ found a good correlation $\left(R^{2}=0.86\right.$; Figure 4$)$ :

$$
S=1.77 \times \text { Bubbling Rate, }
$$

suggesting that calibration for individual measurements may not be necessary once the infiltrometer has been calibrated. Some soil treatments deviated from this relationship, particularly the sandy loam soil packed to $\rho_{\mathrm{d}}=1400 \mathrm{~kg} \mathrm{~m}^{-3}$ and tested dry $(\mathrm{P}<0.05)$.

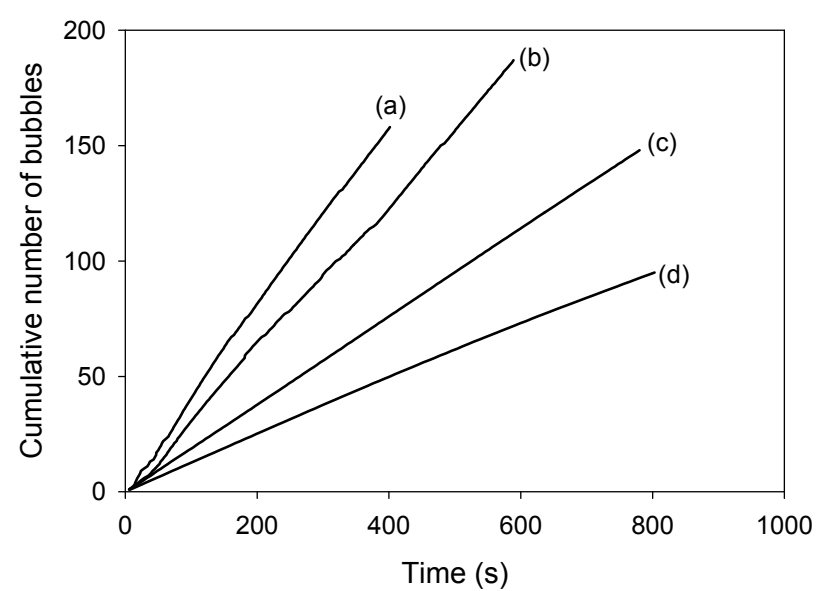

Fig. 2. The number of bubbles formed over time for representative samples of the sandy loam soil at soil bulk density $\rho_{\mathrm{d}}=$ (a) $1200 \mathrm{~kg} \mathrm{~m}^{-3}$, Dry; (b) $1400 \mathrm{~kg} \mathrm{~m}^{-3}$, Dry; (c) $1200 \mathrm{~kg} \mathrm{~m}^{-3}$, water potential $\psi=-50 \mathrm{kPa}$ and (d) $1400 \mathrm{~kg} \mathrm{~m}^{-3}, \psi=-50 \mathrm{kPa}$. All measurements were conducted under a $-7 \mathrm{~cm}$ infiltrometer tension.

Therefore, as good practice it would be valuable for an operator to perform periodic checks.

There are several sources of error that could affect the relationship between $S$ and bubbling rate. The calculation of $S$ by Equation 1 relies on an assumed value of $b$ equal to 0.55 taken by Leeds-Harrison et al. (1994) as an average value to account for wetting front dynamics derived by Wooding (1968). However, wetting front dynamics will vary between soils of different textures, structure and initial water content. Madsen and Chandler (2007) found that water infiltration measurements with a Mini Disk infiltrometer were more sensitive to initial soil water content than larger scale infiltrometers. Another source of error is the sensitivity of the air outlet port where bubbling rates were measured. We attached a plastic tube to the end of the stainless steel needle tubing to increase bubble volume, taking care to minimise asperities at the end of the plastic tube that would affect bubble formation and release. Due to the small size of this tube, however, even small asperities will have a large impact and fouling over time could affect the air-solid-water 
contact angle of the plastic surface or the surface tension of the water in the bubbling chamber. We suggest use of a glass capillary tube for the bubble outlet in future designs and possibly the use of a small concentration of bleach to minimise microbial fouling.

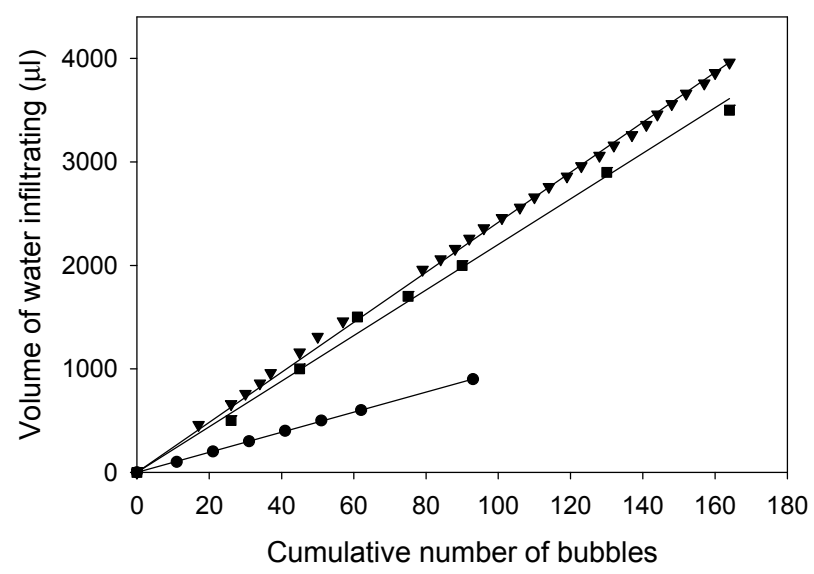

Fig. 3. The volume of water infiltrating from the infiltrometer versus the number of bubbles. From this relationship the bubble volume could be calculated. Data shown are for the sandy loam soil tested at a water potential $\psi=-50 \mathrm{kPa}$ with the infiltrometer tension of $-7 \mathrm{~cm}(\bullet)$, and Dry at an infiltrometer tension of $2 \mathrm{~cm}(\boldsymbol{\nabla})$ and $-7 \mathrm{~cm}(\boldsymbol{\nabla})$. The bubble volumes were $9.70 \mu \mathrm{l}$, $22.02 \mu \mathrm{l}$ and $24.16 \mu \mathrm{l}$ for these data, respectively.

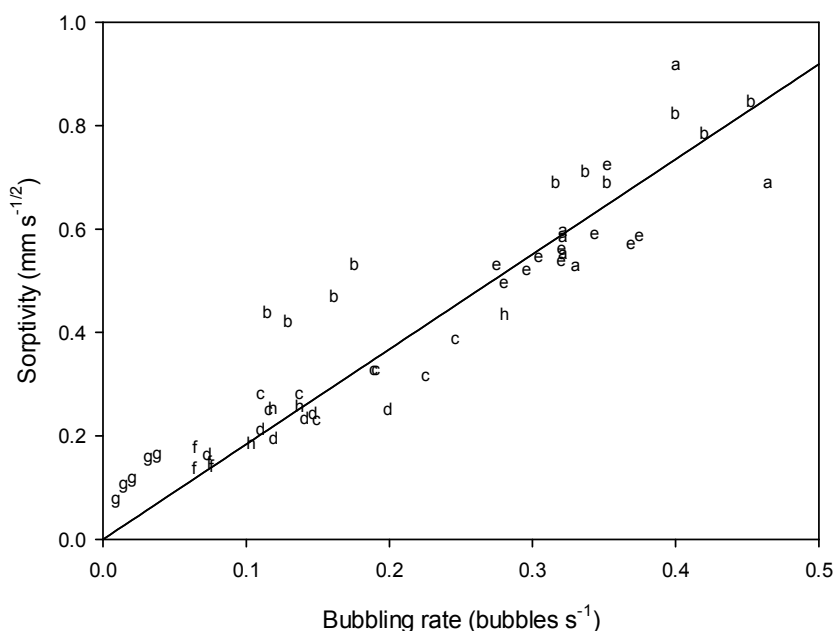

Fig. 4. Sorptivity $S$ in relation to bubbling rate. The letters correspond to the following treatments: sandy loam soil at $-7 \mathrm{~cm}$ infiltrometer tension - (a) soil bulk density $\rho_{\mathrm{d}}=1200 \mathrm{~kg} \mathrm{~m}^{-3}$, Dry; (b) $\rho_{\mathrm{d}}=1400 \mathrm{~kg} \mathrm{~m}^{-3}$, Dry; (c) $\rho_{\mathrm{d}}=1200 \mathrm{~kg} \mathrm{~m}^{-3}$, water potential $\psi=-50 \mathrm{kPa}$; (d) $\rho_{\mathrm{d}}=1400 \mathrm{~kg} \mathrm{~m}^{-3}, \psi=-50 \mathrm{kPa}$; (e) sandy loam soil at $-2 \mathrm{~cm}$ infiltrometer tension and $\rho_{\mathrm{d}}=$ $1400 \mathrm{~kg} \mathrm{~m}^{-3}$, Dry; (f) clay loam soil $-7 \mathrm{~cm}$ infiltrometer tension, $\rho_{\mathrm{d}}=1200 \mathrm{~kg} \mathrm{~m}^{-3}, \psi=-50 \mathrm{kPa}$; and dry sand at $-7 \mathrm{~cm}$ infiltrometer tension and $(\mathrm{g}) \rho_{\mathrm{d}}=1400 \mathrm{~kg} \mathrm{~m}^{-3}$ and $(\mathrm{h}) \rho_{\mathrm{d}}=1600 \mathrm{~kg} \mathrm{~m}^{-3}$.

Nylon mesh was used as the infiltrometer base so that negative water potentials could be obtained. In earlier microinfiltrometer designs, sponge was used for the base for the dual purpose of establishing a negative water potential and improved soil contact (Leeds-Harrison et al., 1994). From our experience, sponge requires greater maintenance as it can be pushed into the infiltrometer tube and its flow rate is heavily dependent on the sponge materials and how it is packed into the infiltrometer (Hallett and Young, 1999; Hallett et al., 2003; Hallett et al., 2004). In the tests reported here, packed soil provided a flat surface so the nylon mesh base provided good soil contact, but on rougher soil surfaces contact could affect measurements.

In summary, the automated microiniltrometer design described provided an inexpensive and easy to construct device to measure small-scale water infiltration properties of soils. There are several opportunities to improve the design and the use of the infiltrometer in practice. Inexpensive optical sensors are available that could be used to measure bubbling rates more accurately. Arrays of microinfiltrometers could provide rapid spatial measurements of small-scale water infiltration (Hallett et al., 2004). A stand that supports multiple infiltrometers vertically and at defined spacings would make an infiltrometer array easier to operate in the field. Water repellency could be measured with the microinfiltrometer by also using ethanol as the infiltrating liquid (Lichner et al., 2013).

\section{REFERENCES}

Arriaga, F.J., Kornecki, T.S., Balkcom, K.S., Raper, R.L., 2010. A method for automating data collection from a double-ring infiltrometer under falling head conditions. Soil Use Manage., 26, 61-67.

Bachmann, J., Goebel, M.O., Woche, S.K., 2013. Small-scale contact angle mapping on undisturbed soil surfaces. J. Hydrol. Hydromech., 61, 3-8.

Bowker, M.A., Eldridge, D.J., Val, J., Soliveres, S., 2013. Hydrology in a patterned landscape is co-engineered by soildisturbing animals and biological crusts. Soil Bio. Biochem., $61,14-22$

Casey, F.X.M., Derby, N.E., 2002. Improved design for an automated tension infiltrometer. Soil Sci. Soc. Am. J., 66, 64-67.

Castiglione, P., Shouse, P.J., Mohanty, B., Hudson, D., van Genuchten, M.T., 2005. Improved tension infiltrometer for measuring low fluid flow rates in unsaturated fractured rock. Vadose Zone J., 4, 885-890.

Doerr, S.H., Ferreira, A.J.D., Walsh, R.P.D., Shakesby, R.A., Leighton-Boyce, G., Coelho, C.O.A., 2003. Soil water repellency as a potential parameter in rainfall-runoff modelling: experimental evidence at point to catchment scales from Portugal. Hydrol. Process., 17, 363-377.

Hallett, P., Young, I., 1999. Changes to water repellence of soil aggregates caused by substrate-induced microbial activity. Eur. J. Soil Sci., 50, 35-40.

Hallett, P., Gordon, D., Bengough, A., 2003. Plant influence on rhizosphere hydraulic properties: direct measurements using a miniaturized infiltrometer. New Phytol., 157, 597-603.

Hallett, P., Nunan, N., Douglas, J., Young, I., 2004. Millimeterscale spatial variability in soil water sorptivity: Scale, surface elevation, and subcritical repellency effects. Soil Sci. Soc. Am. J., 68, 352-358.

Hallett, P.D., Karim, K.H., Bengough, A.G., Otten, W., 2013. Biophysics of the vadose zone: from reality to model systems and back again. Vadose Zone J., 12, 4, doi:10.2136/vzj2013.05.0090.

Johnson, D.O., Arriaga, F.J., Lowery, B., 2005. Automation of a falling head permeameter for rapid determination of hydraulic conductivity of multiple samples. Soil Sci. Soc. Am. J., 69, 828-833. 
Leeds-Harrison, P.B., Youngs, E.G., Uddin, B., 1994. A device for determining the sorptivity of soil aggregates. Eur. J. Soil Sci., 45, 269-272.

Lichner, L., Capuliak, J., Zhukova, N., Holko, L., Czachor, H., Kollár, J., 2013. Pines influence hydrophysical parameters and water flow in a sandy soil. Biologia, 68, 1104-1108.

Logsdon, S.D., Jaynes, D.B., 1996. Spatial variability of hydraulic conductivity in a cultivated field at different times. Soil Sci. Soc. Am. J., 60, 703-709.

Madsen, M.D., Chandler, D.G., 2007. Automation and use of mini disk infiltrometers. Soil Sci. Soc. Am. J., 71, 14691472.

Milla, K., Kish, S., 2006. A low-cost microprocessor and infrared sensor system for automating water infiltration measurements. Comput. Electron. Agr., 53, 122-129.

Moret, D., Lopez, M.V., Arrue, J.L., 2004. TDR application for automated water level measurement from Mariotte reservoirs in tension disc infiltrometers. J. Hydrol., 297, 229-235.

Moret-Fernandez, D., Gonzalez, C., Lampurlanes, J., Vicente, J., 2012. An automated disc infiltrometer for infiltration rate measurements using a microflowmeter. Hydrol. Process., 26, 240-245.
Or, D., Tuller, M., 1999. Liquid retention and interfacial area in variably saturated porous media: Upscaling from single-pore to sample-scale model. Water Resour. Res., 35, 3591-3605.

Pittman, D.D., Kohnke, H., 1942. An automatic self recording infiltrometer. Soil Sci., 53, 429-434.

Prieksat, M.A., Ankeny, M.D., Kaspar, T.C., 1992. Design for an automated, self-regulating, single-ring infiltrometer. Soil Sci. Soc. Am. J., 56, 1409-1411.

Spongrova, K., Kechavarzi, C., Dresser, M., Matula, S., Godwin, R.J., 2009. Development of an automated tension infiltrometer for field use. Vadose Zone J., 8, 810-817.

Thompson, J.A., Bell, J.C., Zanner, C.W., 1998. Hydrology and hydric soil extent within a mollisol catena in southeastern Minnesota. Soil Sci. Soc. Am. J., 62, 1126-1133.

Wooding, R.A., 1968. Steady infiltration from a shallow circular pond. Water Resour. Res., 4, 1259-1273.

Zhao, Y., Peth, S., Hallett, P., Wang, X., Giese, M., Gao, Y., Horn, R., 2011. Factors controlling the spatial patterns of soil moisture in a grazed semi-arid steppe investigated by multivariate geostatistics. Ecohydrol., 4, 36-48.

Received 8 January 2014 Accepted 11 April 2014 